\title{
Obesity and Psoriatic Arthritis: A Narrative Review
}

\author{
Anand Kumthekar (D) Alexis Ogdie
}

Received: April 24, 2020 / Published online: June 3, 2020

(c) The Author(s) 2020

\section{ABSTRACT}

Patients with psoriatic arthritis (PsA) have a higher burden of cardio-metabolic comorbidities like obesity, hypertension, diabetes, and cardiovascular disease compared to the general population. Adipose tissue is thought to promote a chronic low grade inflammatory state through inflammatory mediators like tumor necrosis factor alpha (TNF $\alpha$ ), interleukin-6 (IL6), leptin, and adiponectin. A higher body mass index (BMI) is a risk factor for development of PsA and affects disease activity and response to therapy including both disease-modifying antirheumatic drugs (DMARDs) and tumor necrosis factor inhibitors (TNFi). Obesity has an impact on the morbidity in PsA, particularly cardiovascular and/or metabolic. Patients with PsA have a higher cardiovascular risk and obesity may have an additive impact on morbidity and mortality. This review explores the relationship between obesity and PsA.

Digital Features To view digital features for this article go to https://doi.org/10.6084/m9.figshare.12370133.

A. Kumthekar $(\square)$

Montefiore Medical Center, Albert Einstein College

of Medicine, New York, NY, USA

e-mail: anakumth@montefiore.org

A. Ogdie

University of Pennsylvania, Philadelphia, PA, USA
Keywords: Body mass index (BMI); Cardiovascular risk; Obesity; Psoriatic arthritis (PsA)

\section{Key Summary Points}

Obesity is an important comorbidity in patients with psoriatic arthritis (PSA).

Obesity increases the risk of PsA, possibly related to a higher level of proinflammatory mediators.

Patients with a higher body mass index (BMI) are less likely to achieve minimal disease activity (MDA).

A weight reduction strategy has been shown to improve PsA disease activity along with its other beneficial effects of reducing diabetes, hypertension, and coronary artery disease.

\section{INTRODUCTION}

Psoriasis is a common immune-mediated condition with primary manifestations in the skin. Psoriatic arthritis (PsA) is a chronic inflammatory disease that is associated with psoriasis and affects approximately $10-30 \%$ of patients with 
psoriasis [1]. PsA shares clinical, genetic, and etiopathogenic features with other forms of spondyloarthritis (SpA) including axial spondyloarthritis (axSpA), reactive arthritis, and inflammatory bowel disease (IBD)-associated arthritis. Features of PsA include peripheral arthritis, enthesitis, dactylitis, skin and nail psoriasis, inflammatory back pain (IBP), and extra-articular features like uveitis and inflammatory bowel disease. Beyond extra-articular features, PsA is associated with multiple comorbidities, particularly metabolic comorbidities, including obesity, diabetes, and increased cardiovascular risk [2, 3]. In fact, patients with PsA have a higher prevalence of cardiovascular comorbidities like obesity, hypertension, and hyperlipidemia compared to patients with psoriasis without PsA [4] and compared to the general population [5]. More than $50 \%$ of patients with PsA have at least one comorbidity and around $40 \%$ of patients can have three or more comorbidities [6, 7]. Obesity is among the most prevalent comorbidities in PsA. This may be particularly important as adipose tissue plays a role not only in metabolism but also in immune and inflammatory processes [8].

This narrative provides a review of the burden of obesity in patients with PsA and the relationship between PsA, obesity, and outcomes. In conducting a review of the literature, we searched the Pubmed database using the following terms: "psoriatic arthritis", "obesity", "body mass index", and "cardiovascular disease", and relevant literature was selected for review. This article is based on previously conducted studies and does not contain any studies with human participants or animals performed by any of the authors.

\section{BURDEN OF OBESITY: INCREASED PREVALENCE OF OBESITY IN PSORIATIC DISEASE}

The World Health Organization (WHO) defines obesity as a condition of abnormal or excessive accumulation of fat in the adipose tissue, to the extent that health may be impaired [9]. The estimated prevalence of obesity (BMI $\geq 30 \mathrm{~kg} /$ $\mathrm{m}^{2}$ ) in US adults is $39.8 \%$ according to the Centers for Disease Control and Prevention (CDC) [10]. Available evidence suggests that obesity is a common problem in PsA, even compared to other chronic diseases. A number of studies have reported a higher prevalence of obesity in PsA [5, 11-13]. A claims-based study reported higher prevalence of obesity in PsA compared to rheumatoid arthritis (RA) or psoriasis ( $6.0 \%$ vs $4.4 \%$ vs $3.8 \%$ ) and incidence rates per 1000 patient-years of 32.9 vs 24.4 vs 26.4, respectively [13]. A cross-sectional study of patients with PsA and patients with RA enrolled in the Consortium of Rheumatology Researchers of North America (CORRONA) Registry showed a higher prevalence of obesity in PsA compared to RA (45\% vs 39\%) [12]. Likewise, the mean \pm SD BMI of the PsA group was higher than in RA $\left(30.6 \pm 6.8 \mathrm{~kg} / \mathrm{m}^{2}\right.$ vs $29.3 \pm 6.9 \mathrm{~kg} / \mathrm{m}^{2} ; P=0.004$ ) [12]. A populationbased incidence cohort from Olmstead County reported that $44 \%$ of patients with PsA were obese [11]. The large difference in the prevalence across studies is related to the study design, setting (i.e., claims-based study vs registry-based study vs population-based medical records) and outcome definitions used (i.e., codes vs physician diagnoses). Similarly, Bhole et al. reported that patients with PsA have higher BMI values than those with psoriasis or RA [14].

Psoriasis (without PsA) is also associated with a higher prevalence of obesity. A systematic review aggregating data from 2.1 million study participants $(201,831$ patients with psoriasis) concluded that patients with psoriasis have greater pooled odds ratio (OR) for obesity [1.66 and 95\% confidence interval (CI) 1.46-1.89] compared with those without psoriasis [15]. Additionally, this review found that the prevalence of obesity increases as the severity of psoriasis increases with an OR (compared with the general population) from 1.46 for patients with mild psoriasis to 2.23 for severe psoriasis [15]. Obesity often precedes the diagnosis of psoriasis. In fact, obesity is an established risk factor for development of psoriasis in the general population $[16,17]$. 


\section{WHY IS PSA ASSOCIATED WITH OBESITY?}

The association between obesity and PsA is complex and possibly bidirectional. While obesity has been demonstrated to be a risk factor for the development of PsA [18], studies have also suggested that weight gain may be a consequence of these inflammatory conditions as patients with joint dysfunction may be less inclined to be physical active $[19,20]$. Additionally, we know that enthesitis can be associated with repetitive joint trauma, in particular micro-trauma [21, 22]. Obesity may lead to more weight on the joints, altered mechanics, and repetitive micro-trauma. While this can lead to osteoarthritis (OA), it may also stimulate an inflammatory process [23].

\section{OBESITY AND INFLAMMATION}

Obesity is characterized by chronic inflammation promoting a low grade inflammatory state [24]. There is increasing evidence to suggest that adipose tissue, composed of adipocytes, functions as an active endocrine organ, releasing adipocytokines and pro-inflammatory mediators. Adipokines have diverse physiological functions including regulation of the immune system and inflammatory response [24, 25]. Leptin promotes pro-inflammatory cytokines (interleukin-1 $\alpha$ (IL-1 $\alpha)$, IL-12, tumor necrosis factor alpha (TNF $\alpha$ ), IL-17, IL-6) and suppresses anti-inflammatory cytokines (i.e., transforming growth factor (TGF $\beta)$, IL-10) [26]. On the contrary, adiponectin, adipokine, is believed to have anti-inflammatory effects, especially its low molecular weight iso-form [24]. Lower levels of adiponectin and higher levels of leptin have been reported in patients with psoriasis compared to healthy controls [27, 28]. Additionally, leptin was positively associated and adiponectin was negatively associated with the severity of psoriasis [29]. Beyond these two adipokines, adipose tissue is a source of pro-inflammatory cytokines such as IL- 6 , TNF $\alpha$, and IL-8 [30]. Finally, there may be certain pathways that are more easily activated in obese patients than non-obese patients. In SpA mouse models, endoplasmic reticulum (ER) induces the cellular inflammatory cascade through the c-Jun N-terminal kinase (JNK) pathway [31]. The JNK pathway has been shown to be upregulated in the adipose tissue of obese individuals, leading to immuno-inflammatory responses [32]. Apart from low grade inflammation from adipose tissue, increased mechanical loading on the joints, and a possible link with obesity-related dyslipidemia as suggested in OA are hypothesized as risk factors for PsA [33]. Trauma is a known factor in psoriatic skin lesions and a similar phenomenon has been hypothesized in the development of PsA. The weight load of obesity leads to both increased mechanical stress and risk of local micro-damage. PsA is characterized by enthesitis and obesity is associated with pathology of enthesis in the general population [34]. Patients with psoriasis who are exposed to repeated trauma are at a higher risk of developing inflammatory arthritis [35]. A prospective longitudinal cohort study showed that physical trauma was independently associated with an increased risk of PsA compared with controls (multivariate hazard ratio HR of 1.32 (95\% CI 1.13-1.54) [36]. In summary, adipose tissue is associated with inflammation. There is increased risk and prevalence of autoimmune disease with obesity with the strongest levels of evidence for RA, PsA, psoriasis, and multiple sclerosis $[37,38]$. This may lead to interactions that are associated with the development or management of inflammatory disorders, such as PsA. Similarly biomechanic stress might be another factor linking obesity to PsA which has led to increasing interest in understanding the relationship between obesity and chronic inflammatory diseases like PsA.

\section{OBESITY AS A RISK FACTOR FOR DEVELOPMENT OF PSA}

Several studies have found that obese patients with psoriasis and obese patients in general have an increased risk for the development of PsA [39]. A case control study showed that a higher reported BMI at age 18 years was associated with higher odds of PsA compared to normal-weight individuals independent of control 
variables (OR 1.06, $P<0.01)$ [40]. Another prospective study reported borderline association between obesity and development of PsA (relative risk (RR) 2.02, 95\% CI 0.97-4.24) [41]. In a cohort of US Nurses Health Study II, BMI and central obesity were associated with an increased risk of incident PsA. Compared with BMI less than 25.0, the RR was 1.83 for BMI $25.0-29.9 \mathrm{~kg} / \mathrm{m}^{2}$ (95\% CI 1.15-2.89), 3.12 for BMI $30.0-34.9 \mathrm{~kg} / \mathrm{m}^{2}$ (95\% CI 1.90-5.11), and 6.46 for BMI over $35.0 \mathrm{~kg} / \mathrm{m}^{2} \quad(95 \%$ CI 4.11-10.16) [18]. The UK population-based study of more than 75,000 patients with psoriasis showed that the risk of development of PsA was higher in patients with psoriasis and obesity $\left(\mathrm{BMI} \geq 25.0 \mathrm{~kg} / \mathrm{m}^{2}\right) \quad$ or morbid obesity $\left(\mathrm{BMI} \geq 35.0 \mathrm{~kg} / \mathrm{m}^{2}\right)$ as compared with psoriasis and $\mathrm{BMI}<25 \mathrm{~kg} / \mathrm{m}^{2}$. Compared with patients with psoriasis and BMI $<25 \mathrm{~kg} / \mathrm{m}^{2}$, the RR for developing PsA was 1.09 (0.93-1.28) for BMIs from 25.0 to $29.9 \mathrm{~kg} / \mathrm{m}^{2}, 1.22(1.02-1.47)$ for BMIs from 30.0 to $34.9 \mathrm{~kg} / \mathrm{m}^{2}$, and 1.48 (1.20-1.81) for BMIs $\geq 35.0 \mathrm{~kg} / \mathrm{m}^{2}$ [42].

\section{IMPACT OF OBESITY ON PSA CHARACTERISTICS, DISEASE ACTIVITY AND SEVERITY OF PSA}

Patients with PsA who are obese frequently have higher disease severity. Among 314 patients with PsA, obese patients tended to have a longer time to diagnosis compared to patients with a normal BMI [43]. In a study from the UK, patients who were obese were found to have higher joint counts, C-reactive protein (CRP), Health Assessment Quality-Disability Index (HAQ-DI), and composite measures including Clinical Disease Activity Index for Psoriatic Arthritis (cDAPSA). Additionally, obese patients with PsA are less likely to be in a patient acceptable symptom state as measured by the PsA Impact of Disease (PSAID) [22]. A USA-based study similarly found that obesity was associated with higher PSAID and Routine Assessment of Patient Index Data (RAPID3) scores [44]. Eder et al. reported a higher consumption of nonsteroidal anti-inflammatory drugs in patients with obesity than in normal-weight patients but no significant difference in the swollen and tender joint count and joint damage [45]. An Italian study did not find any difference in the baseline disease characteristics of obese and non-obese patients but the obese group of patients did have higher comorbidities like hypercholesterolemia and hypertriglyceridemia [46]. A dietary intervention study showed significant improvement in disease activity measures like DAS28-CRP, DAPSA, and HAQ-DI [47]. Weight reduction correlated in a dose-response manner with higher ACR 20 response rate and greater reductions in DAS28-CRP and HAQ. On the contrary, a registry-based observational study comparing 1900 obese and non-obese patients with PsA did not show a statistically significant difference in the DAS28 and CRP values but did show a significant difference in the percentage of patients achieving a EULAR good or moderate (EGOM) [48].

\section{IMPACT OF OBESITY ON RESPONSE TO THERAPY}

Patients with obesity have poorer response to treatment, but poorer response to TNF inhibitors in particular [49]. In one cohort study, after adjustment for all the other variables, obesity was associated with a higher risk of not achieving Minimal Disease Activity (MDA) (hazard ratio [HR] 4.90, 95\% confidence interval [95\% CI] 3.04-7.87; $P<0.001$ ) [46] (Table 1). Patients on infliximab were on a dose of $5 \mathrm{mg} /$ $\mathrm{kg}$ which was not adjusted and might have hampered an optimal response. The findings were similar in a cohort of 557 patients that showed obese patients with PsA are less likely to achieve sustained MDA compared to those of normal weight [45]. Additionally, when identifying predictors of response to TNF inhibitors, Ogdie et al. reported that obesity was among the strongest predictors with OR 0.51 (0.33-0.81) for not achieving Clinical Disease Activity Index (CDAI) remission [50]. Furthermore, beyond establishing obesity as a risk factor for non-response to therapy, there is good data to suggest that weight loss can have a significant impact on response. Among obese patients with PsA initiating a TNFi, patients with $5-10 \%$ weight loss had a higher odds of 
Table 1 Impact of obesity on response to therapy

\begin{tabular}{|c|c|c|c|c|c|c|}
\hline $\begin{array}{l}\text { Research article } \\
\text { first author }\end{array}$ & $\begin{array}{l}\text { Number of } \\
\text { subjects }\end{array}$ & $\begin{array}{l}\text { Obese } \\
(\%)\end{array}$ & Outcome & $\begin{array}{l}\text { Effect } \\
\text { size (OR) }\end{array}$ & $95 \% \mathrm{CI}$ & $P$ value \\
\hline $\begin{array}{l}\text { Di Minno et al. } \\
\text { (2013) }\end{array}$ & 270 & $\begin{array}{l}135 \\
(50 \%)\end{array}$ & $\begin{array}{l}\text { Probability of not achieving MDA in } \\
\text { obese vs normal patients }\end{array}$ & 4.9 & $3.04-7.87$ & $<0.001$ \\
\hline Eder et al. (2014) & 557 & $\begin{array}{l}197 \\
(35.4 \%)\end{array}$ & $\begin{array}{l}\text { Probability of achieving MDA in obese } \\
\text { vs normal patients }\end{array}$ & 0.52 & $0.4-0.67$ & $<0.001$ \\
\hline $\begin{array}{l}\text { Ogdie et al. } \\
\text { (2019) }\end{array}$ & 774 & $\begin{array}{l}428 \\
(55 \%)\end{array}$ & $\begin{array}{l}\text { Predictor of CDAI remission in } \\
\qquad \mathrm{BMI}>30 \text { vs } \leq 30\end{array}$ & 0.51 & $0.32-0.81$ & \\
\hline $\begin{array}{l}\text { Di Minno et al. } \\
\text { (2014) }\end{array}$ & 126 & $\begin{array}{l}126 \\
(100 \%)\end{array}$ & $\begin{array}{l}\text { Probability of achieving MDA with } \\
5-10 \% \text { vs }<5 \% \text { weight loss }\end{array}$ & 3.75 & $1.36-10.36$ & 0.011 \\
\hline
\end{tabular}

$O R$ odds ratio

achieving MDA compared to patients who lost less than $5 \%$ of their body weight (OR 3.75). The OR of achieving MDA with greater than $10 \%$ weight loss was 6.67 [51]. This study further supports the causal association of obesity with response to therapy. It is possible that some of this improvement is driven by the patient-reported outcomes (PROs) as patients generally feel better after weight loss. However, regardless of why the improvement in achievement of MDA occurs, there is a need for weight reduction strategies to improve clinical outcomes for our patients [52, 53].

To date, most clinical trials have not found a significant difference in the primary outcome when stratifying by obesity, in contrast with real-world studies, and thus most of the therapies available for PsA are not dose adjusted by weight. However, there are three exceptions: ustekinumab (IV), infliximab (IV), and golimumab (IV) are dosed by body weight [54].

\section{MANAGEMENT OF OBESITY AS A CARDIOVASCULAR RISK FACTOR IN PSA}

We know that a significant portion of patients with PsA are obese and that obesity is a risk factor for PsA. It is crucial to recognize and address comorbidities associated with PsA, such as obesity, because of their implications for disease activity, quality of life, and therapy. Obesity reduction has multiple benefits. In fact, among patients with psoriasis, a reduction in BMI may reduce the risk of PsA. A large PsA cohort study found that reducing BMI over a 10-year period was associated with a reduction in the risk of developing PsA compared with BMI remaining constant over the same period [55]. Patients with PsA are at a higher risk for cardiovascular disease including myocardial infarction and major adverse cardiovascular events (MACE) after accounting for traditional cardiovascular risk factors $[3,56,57]$. The most recent American College of Cardiology/American Heart Association (ACC/AHA) guidelines for the primary prevention of cardiovascular disease have now included psoriasis and other chronic inflammatory conditions as "risk-enhancing factors" for cardiovascular disease as is an elevated C-reactive protein [58]. Clinicians are encouraged to first calculate the 10-year cardiovascular risk (i.e., through use of Framingham Risk Score). Among patients with borderline or intermediate risk, presence of a riskenhancing factor (i.e., psoriasis, RA, lupus, or other chronic inflammatory disorders) should be managed more aggressively (such as earlier initiation of a statin) [59]. While obesity is not directly named as a risk factor, obesity is often associated with other cardio-metabolic conditions (i.e., dyslipidemia, hypertension, diabetes, metabolic syndrome) which are named risk 
factors [60]. This makes cardiovascular risk assessment (as well as assessment for these associated conditions) that much more important. Improving cardiovascular risk assessment techniques in patients with inflammatory arthritis is challenging and has been a topic of ongoing research $[61,62]$.

\section{MANAGE OBESITY IN PATIENTS WITH PSA}

In this paper, we have summarized the impact of obesity on disease activity, response to therapy, cardiovascular risk, and patients' general well-being. However, there are currently relatively few resources for rheumatologists and dermatologists to help patients lose weight. Access to nutritionists to guide dietary interventions is desirable but not always available [53]. Physical activity recommendations for patients with inflammatory arthritis are the same as for the general population [63]. However, physical activity alone tends to have lower effectiveness for weight loss than dietary strategies [64]. Additionally, diets are hard to adhere to and exercise programs are challenging to initiate and maintain [52]. Pharmacological treatment options for obesity are limited. Bariatric surgery is the treatment of choice when all other interventions have failed. Regardless of the type of bariatric surgery performed, its effects on weight loss and associated comorbidities are superior when compared with nonsurgical interventions [65] and initial evidence suggests there is some benefit in psoriasis and PsA [66-68]. However, further studies are needed, specifically, pragmatic interventions to address obesity need to be developed and tested for application in clinical practice.

\section{CONCLUSION}

Obesity and PsA share a complex relationship which is likely bidirectional. Obesity has been demonstrated as a known risk factor for development of PsA in multiple studies. Adipose tissue is metabolically active and produces a chronic low grade inflammation in obese individuals. This chronic low grade inflammation may be responsible for the increased risk for PsA, increased disease burden, and poor response to therapy, but there may be other confounders in this relationship as well (e.g., micro-trauma, general functional impairments from obesity, and worse PROs). Weight loss has been demonstrated to improve the achievement of MDA in patients with obesity initiating a TNFi. Diet and exercise still form the crux of obesity treatment, which can be challenging for our patients. Weight reduction strategies should be encouraged to improve outcomes related to PsA but also to promote the overall health of our patients. Further studies are needed to develop weight reduction strategies that can be applied in clinical practice.

\section{ACKNOWLEDGEMENTS}

We acknowledge the support of Dr. Chaim Putterman, Professor of Medicine, Albert Einstein College of Medicine.

Funding. No funding or sponsorship was received for this study or publication of this article. Dr. Ogdie is supported by NIH/NIAMS R01 AR072363.

Authorship. All named authors meet the International Committee of Medical Journal Editors (ICMJE) criteria for authorship for this article, take responsibility for the integrity of the work as a whole, and have given their approval for this version to be published.

Disclosures. Anand Kumthekar has nothing to disclose. Alexis Ogdie reports Grants from Novartis (to Penn), Pfizer (To Penn), Amgen (To Forward/NDB); Consulting for AbbVie, Amgen, Bristol-Myers Squibb, Celgene, Corrona, Eli Lilly and Company, Janssen, Novartis, Pfizer, UCB, and Takeda.

Compliance with Ethics Guidelines. This article is based on previously conducted studies and does not contain any studies with human 
participants or animals performed by any of the authors.

Data Availability. Data sharing is not applicable to this article as no datasets were generated or analyzed during the current study.

Open Access. This article is licensed under a Creative Commons Attribution-NonCommercial 4.0 International License, which permits any non-commercial use, sharing, adaptation, distribution and reproduction in any medium or format, as long as you give appropriate credit to the original author(s) and the source, provide a link to the Creative Commons licence, and indicate if changes were made. The images or other third party material in this article are included in the article's Creative Commons licence, unless indicated otherwise in a credit line to the material. If material is not included in the article's Creative Commons licence and your intended use is not permitted by statutory regulation or exceeds the permitted use, you will need to obtain permission directly from the copyright holder. To view a copy of this licence, visit http://creativecommons.org/licenses/by$\mathrm{nc} / 4.0 /$.

\section{REFERENCES}

1. Alinaghi F, Calov M, Kristensen LE, et al. Prevalence of psoriatic arthritis in patients with psoriasis: a systematic review and meta-analysis of observational and clinical studies. J Am Acad Dermatol. 2019;80(1):251-65 e19.

2. Jamnitski A, Symmons D, Peters MJ, Sattar N, McInnes I, Nurmohamed MT. Cardiovascular comorbidities in patients with psoriatic arthritis: a systematic review. Ann Rheum Dis. 2013;72(2): 211-6.

3. Ogdie A, Yu Y, Haynes K, et al. Risk of major cardiovascular events in patients with psoriatic arthritis, psoriasis and rheumatoid arthritis: a population-based cohort study. Ann Rheum Dis. 2015;74(2):326-32.

4. Husted JA, Thavaneswaran A, Chandran V, et al. Cardiovascular and other comorbidities in patients with psoriatic arthritis: a comparison with patients with psoriasis. Arthritis Care Res (Hoboken). 2011;63(12):1729-35.

5. Jafri K, Bartels CM, Shin D, Gelfand JM, Ogdie A. Incidence and management of cardiovascular risk factors in psoriatic arthritis and rheumatoid arthritis: a population-based study. Arthritis Care Res (Hoboken). 2017;69(1):51-7.

6. Salaffi F, Carotti M, Gasparini S, Intorcia M, Grassi $\mathrm{W}$. The health-related quality of life in rheumatoid arthritis, ankylosing spondylitis, and psoriatic arthritis: a comparison with a selected sample of healthy people. Health Qual Life Outcomes. 2009;7: 25 .

7. Husted JA, Thavaneswaran A, Chandran V, Gladman DD. Incremental effects of comorbidity on quality of life in patients with psoriatic arthritis. J Rheumatol. 2013;40(8):1349-56.

8. Hauner H. Secretory factors from human adipose tissue and their functional role. Proc Nutr Soc. 2005;64(2):163-9.

9. World Health Organization. Obesity: preventing and managing the global epidemic. Report of a WHO consultation. World Health Organ Tech Rep Ser. 2000;894:i-xii, 1-253.

10. Hales CM, Carroll MD, Fryar CD, Ogden CL. Prevalence of obesity among adults and youth: United States, 2015-2016. NCHS Data Brief. 2017;288:1-8.

11. Ernste FC, Sanchez-Menendez M, Wilton KM, Crowson CS, Matteson EL, Maradit KH. Cardiovascular risk profile at the onset of psoriatic arthritis: a population-based cohort study. Arthritis Care Res (Hoboken). 2015;67(7):1015-21.

12. Labitigan M, Bahce-Altuntas A, Kremer JM, et al. Higher rates and clustering of abnormal lipids, obesity, and diabetes mellitus in psoriatic arthritis compared with rheumatoid arthritis. Arthritis Care Res (Hoboken). 2014;66(4):600-7.

13. Radner H, Lesperance T, Accortt NA, Solomon DH. Incidence and prevalence of cardiovascular risk factors among patients with rheumatoid arthritis, psoriasis, or psoriatic arthritis. Arthritis Care Res (Hoboken). 2017;69(10):1510-8.

14. Bhole VM, Choi HK, Burns LC, et al. Differences in body mass index among individuals with PsA, psoriasis, RA and the general population. Rheumatology (Oxford). 2012;51(3):552-6.

15. Armstrong AW, Harskamp CT, Armstrong EJ. The association between psoriasis and obesity: a systematic review and meta-analysis of observational studies. Nutr Diabetes. 2012;2:e54. 
16. Kumar S, Han J, Li T, Qureshi AA. Obesity, waist circumference, weight change and the risk of psoriasis in US women. J Eur Acad Dermatol Venereol. 2013;27(10):1293-8.

17. Setty AR, Curhan G, Choi HK. Obesity, waist circumference, weight change, and the risk of psoriasis in women: Nurses' Health Study II. Arch Intern Med. 2007;167(15):1670-5.

18. Li W, Han J, Qureshi AA. Obesity and risk of incident psoriatic arthritis in US women. Ann Rheum Dis. 2012;71(8):1267-72.

19. Herron MD, Hinckley M, Hoffman MS, et al. Impact of obesity and smoking on psoriasis presentation and management. Arch Dermatol. 2005;141(12): 1527-34.

20. Kaye JA, Li L, Jick SS. Incidence of risk factors for myocardial infarction and other vascular diseases in patients with psoriasis. Br J Dermatol. 2008;159(4): 895-902.

21. Ash ZR, Tinazzi I, Gallego CC, et al. Psoriasis patients with nail disease have a greater magnitude of underlying systemic subclinical enthesopathy than those with normal nails. Ann Rheum Dis. 2012;71(4):553-6.

22. Van Mechelen M, Lories RJ. Microtrauma: no longer to be ignored in spondyloarthritis? Curr Opin Rheumatol. 2016;28(2):176-80.

23. Russolillo A, Iervolino S, Peluso R, et al. Obesity and psoriatic arthritis: from pathogenesis to clinical outcome and management. Rheumatology (Oxford). 2013;52(1):62-7.

24. Toussirot E, Streit G, Wendling D. The contribution of adipose tissue and adipokines to inflammation in joint diseases. Curr Med Chem. 2007;14(10): 1095-100.

25. Mohamed-Ali V, Pinkney JH, Coppack SW. Adipose tissue as an endocrine and paracrine organ. Int $\mathrm{J}$ Obes Relat Metab Disord. 1998;22(12):1145-58.

26. Lord GM, Matarese G, Howard JK, Baker RJ, Bloom SR, Lechler RI. Leptin modulates the T-cell immune response and reverses starvation-induced immunosuppression. Nature. 1998;394(6696):897-901.

27. Wang Y, Chen J, Zhao Y, Geng L, Song F, Chen HD. Psoriasis is associated with increased levels of serum leptin. Br J Dermatol. 2008;158(5):1134-5.

28. Takahashi H, Tsuji H, Takahashi I, Hashimoto Y, Ishida-Yamamoto A, Iizuka H. Plasma adiponectin and leptin levels in Japanese patients with psoriasis. Br J Dermatol. 2008;159(5):1207-8.
29. Johnston A, Arnadottir S, Gudjonsson JE, et al. Obesity in psoriasis: leptin and resistin as mediators of cutaneous inflammation. $\mathrm{Br} \mathrm{J}$ Dermatol. 2008;159(2):342-50.

30. Toussirot E, Aubin F, Dumoulin G. Relationships between adipose tissue and psoriasis, with or without arthritis. Front Immunol. 2014;5:368.

31. Colbert RA, DeLay ML, Klenk EI, Layh-Schmitt G. From HLA-B27 to spondyloarthritis: a journey through the ER. Immunol Rev. 2010;233(1): 181-202.

32. Sharma NK, Das SK, Mondal AK, et al. Endoplasmic reticulum stress markers are associated with obesity in nondiabetic subjects. J Clin Endocrinol Metab. 2008;93(11):4532-41.

33. Thijssen E, van Caam A, van der Kraan PM. Obesity and osteoarthritis, more than just wear and tear: pivotal roles for inflamed adipose tissue and dyslipidaemia in obesity-induced osteoarthritis. Rheumatology (Oxford). 2015;54(4):588-600.

34. Scott A, Zwerver J, Grewal N, et al. Lipids, adiposity and tendinopathy: is there a mechanistic link? Crit Rev Br J Sports Med. 2015;49(15):984-8.

35. Pattison E, Harrison BJ, Griffiths CE, Silman AJ, Bruce IN. Environmental risk factors for the development of psoriatic arthritis: results from a case-control study. Ann Rheum Dis. 2008;67(5): 672-6.

36. Thorarensen SM, Lu N, Ogdie A, Gelfand JM, Choi HK, Love TJ. Physical trauma recorded in primary care is associated with the onset of psoriatic arthritis among patients with psoriasis. Ann Rheum Dis. 2017;76(3):521-5.

37. Versini M, Jeandel PY, Rosenthal E, Shoenfeld Y. Obesity in autoimmune diseases: not a passive bystander. Autoimmun Rev. 2014;13(9):981-1000.

38. Zingone F, Bucci C, Tortora R, et al. Body mass index and prevalence of skin diseases in adults with untreated coeliac disease. Digestion. 2009;80(1): $18-24$.

39. Scher JU, Ogdie A, Merola JF, Ritchlin C. Preventing psoriatic arthritis: focusing on patients with psoriasis at increased risk of transition. Nat Rev Rheumatol. 2019;15(3):153-66.

40. Soltani-Arabshahi R, Wong B, Feng BJ, Goldgar DE, Duffin KC, Krueger GG. Obesity in early adulthood as a risk factor for psoriatic arthritis. Arch Dermatol. 2010;146(7):721-6.

41. Eder L, Haddad A, Rosen CF, et al. The incidence and risk factors for psoriatic arthritis in patients 
with psoriasis: a prospective cohort study. Arthritis Rheumatol. 2016;68(4):915-23.

42. Love TJ, Zhu Y, Zhang Y, et al. Obesity and the risk of psoriatic arthritis: a population-based study. Ann Rheum Dis. 2012;71(8):1273-7.

43. Eder L, Abji F, Rosen CF, Chandran V, Gladman DD. The association between obesity and clinical features of psoriatic arthritis: a case-control study. J Rheumatol. 2017;44(4):437-43.

44. Walsh JA, Wan MT, Willinger C, et al. Measuring outcomes in psoriatic arthritis: comparing Routine Assessment of Patient Index Data (RAPID3) and Psoriatic Arthritis Impact of Disease (PSAID). J Rheumatol. 2019. https://doi.org/10.3899/ jrheum.190219.

45. Eder L, Thavaneswaran A, Chandran V, Cook RJ, Gladman DD. Obesity is associated with a lower probability of achieving sustained minimal disease activity state among patients with psoriatic arthritis. Ann Rheum Dis. 2015;74(5):813-7.

46. di Minno MN, Peluso R, Iervolino S, et al. Obesity and the prediction of minimal disease activity: a prospective study in psoriatic arthritis. Arthritis Care Res (Hoboken). 2013;65(1):141-7.

47. Klingberg E, Bilberg A, Bjorkman S, et al. Weight loss improves disease activity in patients with psoriatic arthritis and obesity: an interventional study. Arthritis Res Ther. 2019;21(1):17.

48. Hojgaard P, Glintborg B, Kristensen LE, Gudbjornsson B, Love TJ, Dreyer L. The influence of obesity on response to tumour necrosis factor-alpha inhibitors in psoriatic arthritis: results from the DANBIO and ICEBIO registries. Rheumatology (Oxford). 2016;55(12):2191-9.

49. Singh S, Facciorusso A, Singh AG, et al. Obesity and response to anti-tumor necrosis factor-alpha agents in patients with select immune-mediated inflammatory diseases: a systematic review and metaanalysis. PLoS One. 2018;13(5):e0195123.

50. Ogdie A, Palmer JL, Greenberg J, et al. Predictors of achieving remission among patients with psoriatic arthritis initiating a tumor necrosis factor inhibitor. J Rheumatol. 2019;46(5):475-82.

51. Di Minno MN, Peluso R, Iervolino S, et al. Weight loss and achievement of minimal disease activity in patients with psoriatic arthritis starting treatment with tumour necrosis factor alpha blockers. Ann Rheum Dis. 2014;73(6):1157-62.

52. Ogdie A, Asch DA. Changing health behaviours in rheumatology: an introduction to behavioural economics. Nat Rev Rheumatol. 2020;16(1):53-60.
53. Ogdie A, Eder L. The need for strategies to address obesity and psoriatic arthritis prevention in psoriasis. Br J Dermatol. 2020;182(3):523-4.

54. FDA. Highlights of prescribing information for STELARA ${ }^{\circledR}$ (ustekinumab). 2018. https://www. accessdata.fda.gov/drugsatfda_docs/label/2018/ 125261s147lbl.pdf. Accessed 14 May 2020.

55. Green A, Shaddick G, Charlton R, et al. Modifiable risk factors and the development of psoriatic arthritis in people with psoriasis. Br J Dermatol. 2020;182(3):714-20.

56. Ferguson LD, Siebert S, McInnes IB, Sattar N. Cardiometabolic comorbidities in RA and PsA: lessons learned and future directions. Nat Rev Rheumatol. 2019;15(8):461-74.

57. Agca R, Heslinga SC, Rollefstad S, et al. EULAR recommendations for cardiovascular disease risk management in patients with rheumatoid arthritis and other forms of inflammatory joint disorders: 2015/2016 update. Ann Rheum Dis. 2017;76(1): $17-28$.

58. Arnett DK, Blumenthal RS, Albert MA, et al. 2019 ACC/AHA guideline on the primary prevention of cardiovascular disease: a report of the American College of Cardiology/American Heart Association Task Force on clinical practice guidelines. Circulation. 2019;140(11):e596-e646.

59. Stone NJ, Grundy SM. The 2018 AHA/ACC/multisociety cholesterol guidelines: looking at past, present and future. Prog Cardiovasc Dis. 2019;62(5): 375-83.

60. Logue J, Murray HM, Welsh P, et al. Obesity is associated with fatal coronary heart disease independently of traditional risk factors and deprivation. Heart. 2011;97(7):564-8.

61. Akenroye AT, Kumthekar AA, Alevizos MK, Mowrey $\mathrm{WB}$, Broder A. Implementing an electronic medical record-based reminder for cardiovascular risk screening in rheumatoid arthritis. Arthritis Care Res (Hoboken). 2017;69(5):625-32.

62. Majka DS, Lee JY, Peprah YA, et al. Changes in care after implementing a multifaceted intervention to improve preventive cardiology practice in rheumatoid arthritis. Am J Med Qual. 2019;34(3):276-83.

63. Rausch Osthoff AK, Niedermann K, Braun J, et al. 2018 EULAR recommendations for physical activity in people with inflammatory arthritis and osteoarthritis. Ann Rheum Dis. 2018;77(9): 1251-60. 
64. Chin SH, Kahathuduwa CN, Binks M. Physical activity and obesity: what we know and what we need to know. Obes Rev. 2016;17(12):1226-444.

65. Colquitt JL, Pickett K, Loveman E, Frampton GK. Surgery for weight loss in adults. Cochrane Database Syst Rev. 2014;(8):CD003641.

66. Maglio C, Peltonen M, Rudin A, Carlsson LMS. Bariatric surgery and the incidence of psoriasis and psoriatic arthritis in the Swedish Obese Subjects
Study. Obesity (Silver Spring). 2017;25(12): 2068-73.

67. Gallo G, Candilio G, De Luca E, et al. Bariatric surgery and rheumatic diseases: a literature review. Rev Recent Clin Trials. 2018;13(3):176-83.

68. Egeberg A, Sorensen JA, Gislason GH, Knop FK, Skov L. Incidence and prognosis of psoriasis and psoriatic arthritis in patients undergoing bariatric surgery. JAMA Surg. 2017;152(4):344-9. 